\title{
Empatia de enfermeiras com recém-nascidos hospitalizados em unidades de terapia intensiva neonatal
}

Nurses' empathy with newborns hospitalized in neonatal intensive care units Empatía de enfermeras con recién nacidos hospitalizados en unidades de cuidados intensivos neonatales

Leandro Felipe Mufato ${ }^{1}$ (D) https://orcid.org/0000-0002-8693-5637 Maria Aparecida Munhoz Gaíva² iD https://orcid.org/0000-0002-8666-9738

Como citar:

Mufato LF Gaiva MA. Empatia de enfermeiras com recém-nascidos hospitalizados em unidades de terapia intensiva neonatal. Acta Paul Enferm. 2022;35:AAPE00492.

DOI

http://dx.doi.org/10.37689/acta-ape/2022A000492

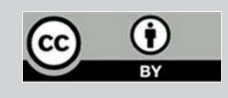

Descritores

Empatia; Enfermagem neonatal; Relaçōes enfermeiropaciente; Unidades de terapia intensiva neonatal

Keywords Empathy; Neonatal nursing; Nurse-patient relations; Intensive care units, neonata

Descriptores

Empatía; Enfermería neonatal; Relaciones enfermeropaciente; Unidades de cuidado intensivo neonata

Submetido 11 de Março de 2020

Aceito

26 de Maio de 202

\section{Autor correspondente}

Leandro Felipe Mufato

E-mail: leandro.mufato@unemat.br

Editor Associado (Avaliação pelos pares): Denise Myuki Kusahara

(https://orcid.org/0000-0002-9498-0868) Escola Paulista de Enfermagem, Universidade Federal de São Paulo, São Paulo, SP, Brasil

\section{Resumo}

Objetivo: Compreender a experiência da empatia de enfermeiras com os recém-nascidos hospitalizados em Unidade de Terapia Intensiva Neonatal.

Métodos: Pesquisa fenomenológica hermenêutica. Foram realizadas 11 entrevistas com enfermeiras de uma Unidade de Terapia Intensiva Neonatal, localizada em Cuiabá/Mato Grosso, Brasil. A coleta ocorreu entre maio e agosto de 2018. Os dados foram analisados de acordo com a análise temática proposta por Max van Manen.

Resultados: As enfermeiras interagem com diversos recém-nascidos durante seu trabalho, destas interações somente algumas ganharam a especificidade de serem significadas como empáticas. Na empatia, as enfermeiras são mobilizadas pelo significado que atribuem à experiência de ver o neonato na incubadora, dentre estes, destacam-se 0 sentido de ter ou não afeto materno, a leitura da expressão do choro, a carga de procedimentos dolorosos sofrida pelo recém-nascido, o tempo de internação e a identificação da dor. A conduta que as enfermeiras tiveram ao serem empáticas expressa uma centralidade afetiva com 0 uso do corpo que dá colo, conversa, acaricia, toca, em parte pela tentativa de suprir a ausência do afeto das mães.

Conclusão: Evidencia-se o trabalho subjetivo da enfermeira nos episódios de empatia, e suas potencialidades em tornar o cuidado de enfermagem humanizado para os recém-nascidos hospitalizados, bem como os desafios e limitações que a empatia pode trazer ao trabalho das enfermeiras.

\section{Abstract}

Objective: To understand the experience of nurses' empathy with newborns hospitalized in a Neonatal Intensive Care Unit.

Methods: This is a hermeneutic phenomenological research. Eleven interviews were conducted with nurses from a Neonatal Intensive Care Unit, located in Cuiabá/Mato Grosso, Brazil. The collection took place between May and August 2018. The data were analyzed according to the thematic analysis proposed by Max van Manen.

Results: Nurses interact with several newborns during their work, of these interactions only a few gained the specificity of being signified as empathic. In empathy, nurses are instructed by the meaning they attribute to the experience of seeing the newborn in the incubator, among them, the meaning of having maternal affection or not, the reading of the expression of crying, the burden of painful procedures suffered by the newborn, the time of hospitalization and the identification of pain stand out. The behavior that nurses had when they were empathic expresses an affective centrality with the use of the body that takes the baby on the lap, chat, caress, touches, partly by trying to supply the absence of mothers' affection.

Conclusion: It is evidenced nurses' subjective work in episodes of empathy, and its potentialities in making nursing care humanized for hospitalized newborns, as well as the challenges and limitations that empathy can bring to nurses' work. 


\section{Resumen}

Objetivo: Comprender la experiencia de la empatía de enfermeras con recién nacidos hospitalizados en unidades de cuidados intensivos neonatales.

Métodos: Estudio fenomenológico hermenéutico. Se realizaron 11 entrevistas con enfermeras de una unidad de cuidados intensivos neonatal, ubicada en Cuiabá, estado de Mato Grosso, Brasil. La recopilación de datos se llevó a cabo entre mayo y agosto de 2018. Los datos fueron analizados de acuerdo con el análisis temático propuesto por Max van Manen.

Resultados: Las enfermeras interactúan con varios recién nacidos durante su trabajo. De estas interacciones, solo algunas recibieron la especificidad de ser entendidas como empáticas. En la empatía, las enfermeras se sienten movilizadas por el significado que le atribuyen a la experiencia de ver al neonato en la incubadora. Entre ellos, se destaca el sentido de tener o no tener afecto materno, la lectura de la expresión del llanto, la carga de procedimientos dolorosos sufrida por el recién nacido, el tiempo de internación y la identificación del dolor. La conducta que las enfermeras adoptaron al ser empáticas expresa una centralidad afectiva con el uso del cuerpo que arropa en brazos, conversa, acaricia, toca, en parte como un intento de suplir la ausencia del afecto de las madres.

Conclusión: Se observa el trabajo subjetivo de las enfermeras en los episodios de empatía y su potencial de hacer que el cuidado de enfermería se vuelva humanizado para los recién nacidos hospitalizados, así como los desafíos y limitaciones que la empatía puede acarrear en el trabajo de las enfermeras.

\section{Introdução}

No campo da saúde, a empatia tem sido objeto de investigações científicas em áreas do conhecimento como medicina, psicologia e enfermagem, sendo que nesta última ainda é pouco explorada entre os profissionais, concentrando as pesquisas com estudantes de graduação. ${ }^{(1,2)}$

$\mathrm{Na}$ enfermagem, a empatia é descrita como um atributo cognitivo e um atributo emocional, ou a combinação de ambos. A cognição na empatia, é a atividade mental que envolve a aquisição e o processamento de informaçóes que levam à um entendimento melhor (do outro, no caso). O aspecto emocional é o compartilhamento da afetação manifesta ao experienciar subjetivamente um sentimento (no encontro com o outro). ${ }^{(3)}$ Mesmo a empatia sendo uma habilidade profissional importante nas relaçóes sociais em saúde, é pouco estudada em como ela se dá nos contextos de práticas profissionais em enfermagem. ${ }^{(1)}$

Outra vertente conceitual sobre empatia vem da filosofia e a coloca como a experiência de uma consciência estrangeira, uma forma de intencionar o outro que permite que a experiência estrangeira seja dada ao empático como uma experiência estrangeira e não como própria. ${ }^{(4)}$ Esse debate conceitual demonstra a polissemia do termo e o caráter interdisciplinar que a empatia vem assumindo na literatura.

Nas Unidades de Terapia Intensiva Neonatal (UTIN) variadas situaçóes requerem empatia das enfermeiras, tais como: o estímulo à permanência dos pais na unidade, a necessidade do toque e o contato físico com os recém-nascidos (RN) por parte dos pais e dos profissionais e, as tentativas de açóes náo farmacológicas para o alívio da dor. A empatia também influencia o modo como a enfermeira lida com as situaçóes de morte na UTIN. ${ }^{(5)}$ Ainda, o método Mãe Canguru adotado nas unidades neonatais favorece o prognóstico do $\mathrm{RN}$ e a participação da mãe nos cuidados de seu filho, ${ }^{(6)}$ colocando ambos, mães e RN hospitalizados, em interação com as enfermeiras, situação na qual a empatia do profissional poderá exercer forte influência na qualidade do cuidado.

Contudo, há ainda poucos estudos que analisam como a empatia se dá para as enfermeiras que atuam em UTIN. Igualmente, ainda mais escassos são os estudos que investigam a empatia destas profissionais em relação aos $\mathrm{RN}$ hospitalizados que estão sob seus cuidados. A própria dimensão cognitiva, presente em algumas explicaçóes sobre empatia, impediria de compreendermos esse fenômeno numa relação em que os pacientes náo podem comunicar verbalmente seus sentimentos e emoções, como é o caso dos neonatos. A comunicação dos bebês se dá pela gestualidade, o que exige experiência do profissional para entendê-la. ${ }^{(7,8)}$

As enfermeiras que atuam em UTIN são atentas e sensíveis às alteraçóes fisiológicas e comportamentais dos RN. Interpretar a linguagem não verbal do bebê é uma ferramenta importante para a implementação das açôes de cuidado. A linguagem corporal dos recém-nascidos pré-termos é lida pelas enfermeiras, e esta interação precisa ser explorada e compreendida, pois traz consequências para a assistência à saúde desses neonatos. ${ }^{(9)}$ A empatia entre enfermeira e $\mathrm{RN}$ poderia influenciar nessa interação e compreensão, denotando a importância de pesquisas sobre o assunto. 
A linguagem corporal dos neonatos ao ser interpretada pelas enfermeiras constitui, assim, a interação peculiar entre profissional e paciente em UTIN, mesmo que estes não façam uso de linguagem verbal. Sobre essa interação e essa forma de conhecer o paciente é que o fenômeno da empatia pode estar, também, situado e influenciando os resultados em saúde. Essa pesquisa parte da seguinte questão: como se dá a experiência da empatia de enfermeiras com bebês internados em UTIN? O objetivo deste estudo foi compreender a experiência da empatia de enfermeiras com os recém-nascidos hospitalizados em UTIN.

\section{Métodos}

Esta investigação ocorre nos moldes de uma pesquisa fenomenológica hermenêutica e foi extraída da tese de doutorado em Enfermagem intitulada "Empatia de enfermeiras em UTIN". A pesquisa fenomenológica é o estudo de como os fenômenos se apresentam para a consciência, a única forma humana de acesso ao mundo. ${ }^{(10)}$

Este estudo fenomenológico é hermenêutico no sentido que não visa exclusivamente descrever como a experiência se dá para a consciência, mas busca encontrar o que as entrevistadas podem nos revelar em direção ao fenômeno estudado. Revelar a direção que algo indica, é interpretá-lo. A expressão descrição fenomenológica sinaliza um intercâmbio entre a descrição pura de um fenômeno (caráter descritivo da pesquisa) e a direção que esse fenômeno aponta, sua interpretação (caráter hermenêutico da pesquisa). ${ }^{(10)}$

Neste estudo investigou-se as experiências de empatia de enfermeiras que atuavam em UTIN, de um Hospital Universitário. A unidade conta com dez leitos de terapia intensiva em neonatologia. O hospital é público, federal, situado em Cuiabá, Mato Grosso, Brasil.

Os critérios de inclusão das pessoas que poderiam ser informantes na pesquisa foram: ser enfermeiro(a) com experiência em cuidados intensivos neonatais por mais de seis meses. Não foram aplicados critérios de exclusão. A partir do primeiro contato com a coordenadora do serviço de enfermagem da unidade foram surgindo as indicaçóes de enfermeiras que atendiam aos critérios. A cada nova entrevista, a enfermeira sugeria a seguinte, que era contatada pelo pesquisador e convidada a participar. Apenas uma das enfermeiras convidadas não aceitou participar da pesquisa, porém, as entrevistas concedidas permitiram qualidade de informaçóes suficientes para responder ao objetivo do estudo.

As entrevistas individuais seguiram as recomendaçôes da abordagem fenomenológica em pesquisa e foram gravadas em aparelho de registro de áudio digital para posterior transcrição. ${ }^{(10,11)} \mathrm{O}$ tempo de duração das entrevistas variou entre quarenta minutos a duas horas e quarenta minutos e iniciaram-se por meio da seguinte questáo norteadora: conte-me o que você tem experienciado em relação à empatia no cuidado com bebês e seus familiares? A condução destas se deu pelo pesquisador e primeiro autor deste estudo que não possuía nenhum contato prévio com as enfermeiras. A coleta de dados ocorreu no anexo didático do hospital, que contava com salas de aula que puderam ser reservadas para essa finalidade. A exceção sobre o local deu-se com duas enfermeiras, uma preferiu conceder a entrevista em sua casa, a outra, optou por uma sala de reunióes do hospital. Durante esses encontros estiveram presentes somente a enfermeira e o pesquisador. A coleta de dados ocorreu entre maio à agosto de 2018. O critério do poder da informação foi observado com vistas à alcançar o objetivo do estudo, sendo que o trabalho de campo foi encerrado com a décima primeira entrevista. ${ }^{(12)}$ Todas as informantes da pesquisa eram enfermeiras, experientes em cuidados neonatais.

A análise dos dados se deu de acordo com a análise temática em pesquisa fenomenológica hermenêutica proposta por Max van Manen. O tema é um aspecto da estrutura da experiência. Portanto, é algo que nos indica alguma coisa sobre a experiência estudada, e pode nos sinalizar a direção da própria experiência. Um tema pode ser entendido como uma forma de sumarizar de modo inadequado, em linguagem científica, uma simplificaçáo da experiência investigada. Ele, também, pode ganhar contornos de ser algo encontrado em certo momen- 
to em um texto, não uma mera coisa ou união de unidades de significado. Ainda, pode ser uma forma de nos encontrarmos com o fenômeno que pretendemos compreender. ${ }^{(10)}$

Quando se começa a discernir temas no estudo fenomenológico, salienta-os nos discursos dos participantes, nas frases que apontam para este tema, que o aludem, que o sugerem, que captam uma declaração do sentido. ${ }^{(10)} \mathrm{A}$ análise dos dados sumarizou a experiência empáticas das enfermeiras com recém-nascidos hospitalizados em UTIN em dois temas, apresentados nos resultados. Essa sequência de discernir, destacar, sumarizar e organizar os temas em um texto científico se deu concomitante a coleta de dados. Após o término da mesma, ainda foi necessário se debruçar sobre os temas sumarizados para organizá-los como um texto capaz de expressar a compreensão sobre a experiência da empatia.

Em todas as etapas desta pesquisa foram atendidos os princípios éticos, conforme a Resolução $\mathrm{n}^{\mathrm{o}}$ 466/2012 do Conselho Nacional de Saúde, com aprovação do protocolo de pesquisa pelo Comitê de Ética em Pesquisa (CEP) com Seres Humanos, Parecer No 2.624.217 (Certificado de Apresentação para Apreciação Ética: 86136418.0.0000.5541). Os nomes das participantes foram substituídos pela letra "E", e sequenciados pela numeração de cada entrevista (E1, E2, E3, ...E11).

\section{Resultados}

As enfermeiras participantes do estudo possuíam entre quatro e 25 anos de formadas. O tempo de atuação profissional na UTIN do local do estudo variou entre um e 16 anos. Quatro entrevistadas atuavam no turno vespertino, duas no turno matutino, três no período noturno e duas ocupavam cargos de gestáo no hospital no momento da coleta dos dados. A maioria delas era casada (07), as demais solteiras (04). Apenas três enfermeiras possuíam especialização em neonatologia. $\mathrm{O}$ trabalho em UTIN tem a característica de colocar sob a responsabilidade de um único profissional, o enfermeiro, vários recém-nascidos em seus leitos hospitalares, incubadoras.
Para as participantes deste estudo a empatia não se dá com todos eles, o que confere a relação empática entre enfermeira e RN uma especificidade. Essa especificidade ocorre a partir da percepçáo de algo que as mobiliza, a intencionalidade da consciência volta-se para o RN em questão. A primeira temática dos resultados trata dos aspectos mobilizadores do $\mathrm{RN}$ que levam as enfermeiras a agirem empaticamente. No segundo tema, a conduta empática foi explorada, ou seja, as açóes que, quando realizadas, foram rememoradas e compreendidas por elas como empáticas.

\section{A mobilização das enfermeiras diante do recém-nascido na incubadora, nas interações compreendidas como empáticas}

A presença ou ausência da mãe ao lado da incubadora é algo percebido pelas enfermeiras. $\mathrm{O}$ recém-nascido sozinho em sua incubadora, sem os pais ou um acompanhante, aparece na percepção das profissionais como mobilizador das açóes compreendidas como empáticas por elas. Por um lado, é a percepção de um recém-nascido cuja mãe é ausente na UTIN que chama a atenção, fazendo com que a enfermeira se imagine ser sua mãe, para supri-lo nesta ausência. Por outro lado, a mãe que é presente e participativa, também atrai a atenção delas. Vejamos:

"Eu percebo que eu tenho mais facilidade de... de me envolver... quando ele é abandonado pelos pais, o que aqui tem muito. [...] como seria se ele tivesse mãe? Ai, eu pego ele como se fosse a mãe dele pegando."(E2)

"Tipo, o Leito 6, que a mãe está aqui o tempo todo [...] eu vou tocar? Vou tocar. Só que o bebê da Dona Clarinda, eu vou dar mais. Porque ela (a bebê) não tem ninguém por ela ai, nesse momento."(E5)

"Talvez aquele que a mãe não vem, que fica mais tempo sozinho."(E8)

"As que são presentes. É um consolo para quem cuida. Porque ali você começa a ver que poxa, ela está desempenhando o papel de mäe, mesmo sem experiência, mesmo tendo outros filhos em casa."(E8) 
"E a luta dela me... Tipo, me comoveu muito porque o jeito que ele estava, a gravidade dele. E ela não saía de perto. [...] Aquilo me comoveu, me chamou a atenção, de eu começar a conversar com ela. "(E10)

Observou-se que o significado de receber carinho da mãe é algo especial, isso leva a enfermeira a perceber a ausência da mãe em decorrência da preocupação com a falta desse carinho para o bebê. Veja:

"[...] eu tenho assim, um diferencial com aquele que eu percebo que não tem a afetividade materna. [...] aquela criança que não tem o afeto, que deveria ter, uma que não tem a presença dos pais, ou da mãe. No meu caso, eu friso muito a máe porque o carinho de máe é diferente de carinho de pai. Meu ponto de vista."(E5)

"Miniel é uma criança que está ai e, assim, tem pai? Tem pai. O pai nunca veio ai. Tem mãe? Tem mãe. A mãe vem como se fosse uma visita. Não vem diariamente. [...] Aí, é complicado. Ai, onde que fica o carinho?"(E5)

Evidenciou-se que o quadro clínico grave, como o adoecimento por câncer em um recém-nascido, também foi relatado como um caso que despertou a empatia:

"Ai, teve um bebê que ele nasceu com sarcoma. Ele nasceu com uma massa entre a bolsa escrotal e o ânus. Enorme, enorme! Ele já nasceu com câncer. E ai, já fez a colostomia, e assim, foi... Eu nunca tinha visto isso, sabe? Ai, todo mundo se apegou."(E2)

O choro do recém-nascido também surge como mobilizador, que desperta o interesse da enfermeira por um bebê. Vamos ver como ele aparece nessas experiências:

"Porque acontece mais, por exemplo, quando o bebê está chorando. Quando um bebê está passando mal."(E4)

"Estou dizendo por que se tiver chorando muito eu vou lá e pego ele e fico com ele no colo. Se der condiçóes de fazer o método Canguru, eu ponho ele e vou fazendo o que dá para fazer o administrativo eu ponho ele aqui dentro, em mim, e faço."(E5)

"Acho que é a hora em que... Você mais se envolve. A gente até brinca às vezes, sempre tem um que chora mais. Ai, esse ganha o colo de todo mundo."(E6)

"E, esses bebês são os que mais choram, os que não têm a presença de um acompanhante. Esse é que você tem que pegar mesmo." (E10)

A percepção de que a hospitalização do recém-nascido causa a quebra do vínculo entre ele e sua mãe também mobiliza a enfermeira nas experiências descritas como empatia. Conforme segue:

"Você já vê que, é... precocemente já foi separado ali no momento do vinculo entre a máe e o filho. Então, você já se aproxima daquele bebê, começa com o toque. Conversar, a gente conversa..."(E4)

Observou-se a empatia surgir também como uma característica do próprio trabalho de enfermagem em neonatologia, independentemente de ser um recém-nascido acompanhado ou não, choroso ou não. Vejamos:

"Criança né! A gente acaba se comovendo mais. $E$, eu acho que você acaba se envolvendo com o familiar. É diferente do olhar que você tem por um adulto. [...] eu acho que é mais fácil você acolher essa criança. [...] É aquele serzinho ali que está tão indefeso que você acaba querendo, acaba adotando mesmo. Principalmente os prematuros que acabam ficando mais na UTIN, enfim."(E6)

O tempo de internação mais longo também influencia, pela maior possibilidade de envolvimento. A carga de procedimentos dolorosos que são realizados com esse recém-nascido também mobiliza a enfermeira.

"Aqueles que estão internados há mais tempo, que você já prestou um cuidado maior, que já teve um tempo de convivência maior [...] Então a gente 
meio que se mobiliza mais com ele, porque ele ficou mais exposto à procedimentos dolorosos."(E8)

"Os que ficam mais tempo, a gente acaba criando essa empatia, esse vínculo também." (E10)

A empatia aparece também nas entrevistas associada à uma competência clínica de enfermagem, o que faz a enfermeira pensar na sensibilidade para as questôes clínicas (dor, fome, sono, desconforto, alteraçōes fisiológicas). É essa percepçáo de um neonato dentro da incubadora em uma UTIN, um ambiente estressante, que desperta para imaginar-se como sendo alguém dentro daquela incubadora.

"É porque imagina você deitado dentro de uma incubadora... Empatia é você se colocar no lugar, né? Da pessoa, daquele ser humano que tá ali, né? Então, imagina você, com sua pele extremamente exposta, você náo tem pelos, você praticamente não tem epiderme, imagina você sendo tocado, manipulado toda hora. Você náo vai estar sentindo dor? Que você gostaria que fizesse com você??"(E3)

As enfermeiras participantes deste estudo são responsáveis, cada uma, por 05 leitos de UTIN durante seu turno de trabalho. Dentre os $05 \mathrm{RN}$ que assistem, aqueles que estão só, sem visitas ou sua mãe ao lado, ou aqueles cuja mãe está lutando para permanecer ao seu lado e cuidar dele, capta a intencionalidade da enfermeira, mobiliza-a.

Além do afeto materno, o choro, o quadro clínico grave, o tempo de internação e a carga de procedimentos dolorosos, e o próprio estar em uma incubadora também despertam a atenção da enfermeira para agir empaticamente.

\section{A empatia de enfermeiras com os recém- nascidos: a conduta empática}

Este tema trata da compreensão das entrevistadas sobre como foram as situaçôes de empatia vividas por elas. Há uma centralidade da ação, o que se denominou aqui de conduta empática. A experiência da empatia surge como uma forma de apego ao recém-nascido, um envolvimento afetivo, que motiva a enfermeira a agir ao mimar, tocar, conversar e fazer carinho:

"Quando eu me apego... É... até estranho assim, porque, quando eu gosto da criança, tipo, de ficar pegando mesmo, e ficar mimando. [...] Eu converso, eu tento falar, pegar. [...] tipo, eu vou avaliar a fontanela, já faço um carinho na cabeça."(E2)

"Então, você já se aproxima daquele bebê, começa com o toque. Conversar, a gente conversa..., falo. [...]Ai, já vai criando a empatia. Começa no bebê para depois vir o resto. [...] Um carinho que você tem pelo bebê. A gente dá muito carinho, pega no colo. Quando é possivel pegar no colo, a gente pega."(E4)

$\mathrm{Na}$ conduta empática, dar colo ao $\mathrm{RN}$ é uma ação importante. Para algumas enfermeiras, o bebê precisa receber colo, carinho, toque e contato pele a pele. Por isso, ela se volta para aqueleque possui essa necessidade de colo. Atender essa necessidade de afeto é compreendido como ser empática com o RN. Vejamos:

"Eu falo assim: que o bebê adora um colo. O colo é muito bom. O bebê está chorando, você vai lá... Vamos supor uma situação do bebê que está estável. Está chorando, você vai lá pega ele no colo, pega na mãozinha, você conversa com o nenê." (E4)

"Eu acho que faz bem esse carinho, essa interação. Você fazer um carinho na cabeça. Na mãozinha, no pezinho, conversar com ele. Isso aí.. Pegar no colo quando tá chorando. [...]Eu pego no colo, eu não consigo, se tiver um bebê chorando eu vou lá e pego no colo."(E4)

A empatia também surge quando a enfermeira faz uma avaliação clínica sensível, capacidade esta desenvolvida com a experiência profissional. Neste sentido, a empatia fala de um cuidado mais minucioso, atencioso, quando elacuida de um bebê como gostaria que cuidassem dela. E o olhar clínico está na avaliação que ela consegue fazer com os sinais que o neonato lhe dá, como o próprio choro, por exemplo: 
"Eles não falam! Mas você percebe pelo choro, pela reação da face. Pela coloração da pele, pela irritabilidade. Tudo isso é forma de verificar a dor. Então, se eu fosse um prematuro a primeira coisa que eu gostaria que amenizassem minha dor."(E3)

"Ele não vai te falar. Você vai ter que olhar para ele e observar. Está irritado? Como que está esse choro dele? Está contínuo? Está... A gente fala que é um "choro intermitente"? Cor da pele? Está cianótico, pálido? A temperatura está como? Até com frio ele chora! Então é a percepção."(E3)

Há, ainda, uma percepção de que a empatia deve ser evitada, por trazer perda, sofrimento e luto para a enfermeira:

"É... a gente se apega sim, sabe? E, tenta não... tenta! A gente tem que se esforçar a não se apegar. Porque se apega a todo mundo. Você tem que tentar falar: 'Não, eu não quero não." (E2)

"Porque quando eu me apego, eu sofro demais [...] $E$, assim, então, o que acontece: eu tento não me envolver."(E2)

Esta temática da experiência empática com o RN em UTIN demonstra que algumas ações cotidianas das enfermeiras são interpretadas por elas como empatia. Nessa compreensão, o agir com o corpo, que dá colo, carinho, toca e conversa, emergiu como importante para perceber a dor e o que o RN está necessitando e vivenciando. Evidencia-se uma experiência de envolvimento afetivo, e que em alguns casos pode ser evitado pela enfermeira pelo efeito negativo que esse envolvimento pode trazer para ela.

\section{Discussão}

A análise da estrutura da experiência da empatia, partiu da descrição do que se mostra à consciência das enfermeiras participantes deste estudo, ou seja, o fenômeno aí: o sentido atribuído aos recém-nascidos em suas incubadoras nos casos de empatia.
Como fenomenólogos, a preocupação está centrada no como as coisas são vistas, e não o que se vê. ${ }^{(13)}$ Assim, o ambiente da UTIN deste estudo é a mesma realidade vista por todas as enfermeiras participantes. Mas, o ver delas dentro do âmbito da experiência empática é o que se desvendou, no alcance de nossa própria interpretação sobre as suas experiências. Em outras palavras, o recém-nascido dentro da incubadora sozinho é "o que se vê". A falta de carinho de mãe, uma mãe ausente, a quebra de um vínculo entre mãe e filho, a fragilidade e vulnerabilidade do recém-nascido, a dor e o desconforto causada pelo ambiente da UTIN, a falta de família, o não ter ninguém por ele, é "o ver" das enfermeiras sobre isso. A exposição dos fenômenos que se revelam nas entrevistas é o que se vê do mundo, pelas enfermeiras, e não mundo em si.

$\mathrm{Na}$ análise da estrutura da experiência da empatia, nota-se que há algumas marcas (índices) que neonatos carregam e que chamam a atenção das entrevistadas. A empatia neste estudo revela-se um fenômeno, por ser um evento, real, que se dá em determinadas relações sociais de interação entre a enfermeira e os recém-nascidos na UTIN. A empatia é um sentido dado à uma relação vivida, quando o outro se apresenta à consciência desta profissional e mobiliza-a.

Empatia com recém-nascidos em UTIN não é um modo especial de percepção do outro, é o que torna o outro especial na experiência das enfermeiras. Ela não tem relevância por ser um modo de percepção outro dirigida, mas por ser uma percepção do outro que se torna especial para o empático, de acordo com a mobilização que ele lhe causa, permitindo-lhe agir pelo outro.

Nossos resultados sugerem que há uma situação do RN internado em UTIN que desperta a atenção das enfermeiras, abrindo a possibilidade da experiência da empatia. O RN cuja mãe é ausente tem seu espaço, ele as desperta para o envolvimento afetivo e as levam a agir de modo empático. A imagem do bebê sozinho ganhou forma significativa nas experiências de empatia, ele sinaliza para as participantes da pesquisa fragilidade e vulnerabilidade, possuindo poder de despertar o envolvimento afetivo. 
Essa mobilização da enfermeira é algo que é coerente com uma empatia que indica envolvimento afetivo com os neonatos. Há um aspecto dessa experiência que diz da necessidade de um bebê receber carinho de mãe, afeto, colo, toque. Assim, a empatia de enfermeiras com RN internado em UTIN opera por meio de um processo afetivo e emocional, como já vislumbrado em outros contextos. ${ }^{(3)} \mathrm{O}$ componente cognitivo, contudo, que permitiria conhecer melhor a experiência do outro, ganha uma compreensão diferente, e a tomada de perspectiva do empatizado pelo empático tem contornos próprios neste cenário.

Alguns fenomenologistas afirmam que a empatia pressupóe uma diferenciação da experiência entre o eu e o outro (self and the other), ${ }^{(14)}$ talvez na interação com um neonato nós não possamos afirmar a empatia nesses termos, precisamente porque não podemos assegurar qual é a experiência do recém-nascido internado em UTIN, e como ela é vivida por ele. ${ }^{(15)}$

Já se demonstrou que o cuidado de enfermagem à um neonato pode ser entendido como dar uma resposta afetiva ao seu comportamento, algo que está em vista pela equipe ao prestar cuidados em UTIN. ${ }^{(8)}$ A condição de fragilidade e vulnerabilidade que torna o RN dependente de outro ser humano, bem como sua capacidade interativa, vai influenciar na construção de um vínculo afetivo e de apego entre a enfermeira e o bebê, o que foi compreendido como ser empática com os neonatos.

As enfermeiras participantes deste estudo descrevem sua empatia como envolvimento com um recém-nascido, que se diferencia para elas entre os demais neonatos em uma UTIN. Se houvesse um objeto da experiência do bebê (ausência da mãe e familiares como vivida pelo $\mathrm{RN}$ ), este objeto seria dado de modo indireto para a enfermeira, que o lê nas expressóes de choro, esse, por sua vez, dado de modo perceptual.

Dessa forma, o choro de um bebê é dado de modo perceptual para a enfermeira, mas o motivo do choro seria dado indiretamente: o estar separado de sua mãe, estar sem carinho de mãe, estar só. A empatia como a percepção de uma consciência estrangeira poderia clarificar esse processo, ${ }^{(14)}$ a expressão do neonato interpretado pela enfermeira é o que lhe daria indiretamente o objeto da experiência do bebê. Não obstante, este está estruturando sua vida psíquica, o que limita estas explicaçôes da empatia nos casos de enfermeiras com seus pacientes recém-nascidos em UTIN.

Não sabemos como a dor é vivenciada por um recém-nascido, assim como não podemos descrever sua experiência da separação da mãe. Não da mesma maneira que uma criança ou um adulto vivenciam-na. O bebê, enquanto um sujeito em estruturação psíquica expressará seu sofrimento na organização corporal, na manifestação dos reflexos, nos hábitos de sono e alimentação, ou seja, seu sofrimento é observável, não inefável. Além disso, a internação em UTIN pode acarretar para ele uma desorganização de seus hábitos, como hora de dormir e hora de comer, de seus reflexos, como da sucção, e principalmente, $o$ lugar simbólico que ele ocupa para seus pais. ${ }^{(7)}$

Observamos que as enfermeiras entrevistadas interpretam a gestualidade do corpo do neonato internado na UTIN. No entanto, essa é feita mais por meio de suas vivências e do mundo da vida cotidiano, e menos por alguma técnica que permita reconhecimento de sofrimentos psíquicos. As enfermeiras aprendem a conhecer seu paciente, assim como uma mãe aprende a interpretar o choro do seu filho, pela experiência.

Estudo que investigou, por meio de pesquisa fenomenológica, a intencionalidade da equipe de enfermagem ao cuidar de paciente internado em UTIN, demonstrou que o RN pode ser percebido pelo cuidador como alguém que possui suas próprias necessidades. Estas necessidades são expressas pelo comportamento do neonato e as reaçôes à ele requerem, além de conhecimento científico e habilidade técnica, a intuição, a percepção, a responsabilidade e sensibilidade. ${ }^{(8)}$

O choro do bebê é importante no trabalho dos profissionais que atuam em neonatologia, independentemente do significado expresso nesse choro, ou se podemos atribuir alguma experiência ao $\mathrm{RN} .{ }^{(15)} \mathrm{A}$ leitura da enfermeira não se dá somente na expressão do neonato que chora, mas da cena "bebê em sua incubadora sozinho", o que lhe dá notícia de que uma mãe não vem visitar seu filho recém-nascido internado.

Nossos achados sugerem que no mundo da vida cotidiana e pré-reflexivo, se entendêssemos a empatia 
como modo de perceber o outro ${ }^{(14)}$ tornaríamos todas as relaçôes e interaçôes sociais na UTIN iguais, pois ela seria o modo pelo qual eu percebo, e náo fala da qualidade do que é percebido para quem está percebendo. Isso seria negar o que as enfermeiras descreveram sobre os episódios de empatia, quando o outro deixou de ser só mais um percebido, e passou a receber uma orientação da intencionalidade outro dirigida. ${ }^{(16)}$

Para as enfermeiras que atuam em UTIN, a empatia se revela um vínculo afetivo capaz de objetivar que um RN não sofra com a separaçáo de sua mãe. Ser um vínculo afetivo que faça a enfermeira querer que as mães estejam junto com seus filhos, e empoderem-se de sua maternalidade. Um vínculo afetivo que procure de algum modo, evitar o abandono de um bebê pelos pais.

As ações dentro da UTIN que receberam o sentido de ser a experiência da empatia pelas enfermeiras estudadas, agentes desta ação, são expressôes do corpo. Usam o corpo para serem empáticas com os bebês. Independentemente do caráter da mobilização, o que passamos a destacar aqui é o aspecto corporal e afetivo que a empatia possui para essas profissionais. Por sua vez, pesquisa evidenciou que o carinho, o afeto e a atenção são as expressóes das características que a equipe de enfermagem vê nos cuidados ao RN. ${ }^{(8)}$

$\mathrm{O}$ aspecto da empatia como sensibilidade clínica, que também aparece em nossos achados, não se preocupa com o estar só de um bebê, mas se a enfermeira consegue amenizar sua dor, seu desconforto. $\mathrm{Na}$ empatia como sensibilidade clínica, a enfermeira cuida como ela gostaria de ser cuidada. Neste sentido, o olhar clínico para as expressóes do bebê, como o choro, é o que permitirá sensibilizar-se com sua dor, e identificar se ele sente dor ou desconforto.

$\mathrm{O}$ que ocorre em relação à identificação da dor já foi evidenciado em outro estudo sobre o manejo da dor em RN por enfermeiros. Trata-se de uma leitura e interpretação não somente de alteração de padróes fisiológicos, como a queda da saturação, mas igualmente das expressóes corporais, do comportamento e, também, do choro. Uma interpretação feita pela enfermeira, sem o uso de escalas ou conhecimento científico aplicado. ${ }^{(17)}$

E, uma compreensão nos alcança, a de que quando a empatia é algo que permeia o fazer em enfermagem, que melhora e aguça a sensibilidade da enfermeira para cuidar do neonato, com vistas à uma boa prática clínica, não há uma característica dos bebês que chame a atenção, tal como estar sem os pais, pois todos são assistidos. Este aspecto está presente quando a empatia é o modo da enfermeira exercer suas atividades junto aos bebês.

Ponderamos que a clínica aparece aqui como um conhecimento que visa o patológico, os padróes fisiológicos, o bom reconhecimento da situação de saúde com base nos parâmetros e nas expressões do bebê. Uma empatia como sensibilidade para a dor do RN. E, a clínica se contrapóe à perspectiva do envolvimento afetivo de algum modo, pois quando a empatia entra de braços dados com a clínica para algumas enfermeiras participantes deste estudo, o colo, o toque, o carinho e a conversa se escondem pelos cantos. Como se a boa competência clínica diminuísse o componente afetivo da empatia. Vale notar que as enfermeiras que colocam a empatia como um envolvimento afetivo não nos sinalizam de que sua clínica é pior ou melhor por conta disso, apenas afiançam que são mais interessadas no outro e nas interaçóes para além do atendimento clínico, portanto, mais humanas. Ademais, também vislumbramos o aspecto negativo do envolvimento afetivo, quando a enfermeira procura não se envolver, e ser empática, em decorrência de significar este envolvimento como algo que lhe trará sofrimento.

\section{Conclusão}

Os episódios empáticos se dão num jogo dinâmico de percepção da enfermeira e mobilização desta para agir pelo outro. Somente houve empatia quando a percepção de uma situação mobilizou a enfermeira em um determinado envolvimento afetivo, seguido de uma ação em direção ao RN, como tocar, dar colo, carinho, conversar, observar sinais de dor. A empatia aqui revelada, uma forma de tornar o RN especial na percepção da enfermeira, remete ao quanto prestar atenção ao outro se configura como algo que está sob o julgo de cada enfermeira, por sua conta. Concluise que tornar a prática profissional de enfermagem humanizada e empática é um desafio, pelo âmbito da diversidade de situaçóes que mobilizam uma enfer- 
meira para ser empática com o RN, e de como podemos contribuir com a formação destas profissionais para lidarem com esses pacientes. A pesquisa também apontou um aspecto negativo da empatia, quando o envolvimento afetivo com o $\mathrm{RN}$ trouxe sofrimentos, pela perda, por exemplo, e, ainda, temos as enfermeiras que atribuem à empatia uma visão de sensibilidade quase que estritamente técnica, de reconhecimento da dor e desconforto do bebê. O que entendemos então é que se faz necessário acolhermos as enfermeiras da UTIN para que elas recebam de algum modo, suporte para o trabalho subjetivo que realizam ao cuidar de filhos recém-nascidos, vivenciando o começo da vida e a presença constante do medo da morte, e da morte. Ainda, há a necessidade de ampliarmos a discussão sobre humanização e empatia em UTIN, para ir além do controle do ambiente estressante para o RN, ou de uma destreza técnica e identificação da dor como forma estrita de ser empática. Neste estudo o que torna uma enfermeira empática não são as coisas, a tecnologia, os lugares e espaços, a presença ou não de estrutura, ser capacitada ou especialista em alguma área do conhecimento. O que as torna empáticas são as significações que mobilizam ao perceber o RN na incubadora, estas lhe permitem um olhar que consegue ver as cores do afetivo na relação com os bebês em uma UTI neonatal. Ao descrever a experiência da empatia nos modos como ela se apresenta à consciência da enfermeira, avançamos na descrição e compreensão desse fenômeno. Este estudo possui como limitaçóes, a homogeneidade das características das enfermeiras entrevistadas, todas do sexo feminino. Sugere-se novas pesquisas com participantes com diferentes características, o que poderia ampliar a compreensão sobre a ocorrência de empatia de enfermeiros no cuidado neonatal com os RN. Contudo, esse estudo contribui para o debate sobre a interação das enfermeiras com seus pacientes em neonatologia, algo ainda pouco explorado na literatura.

\section{Colaborações}

Mufato LF e Gaíva MAM contribuíram com a concepção do estudo, análise e interpretação dos dados, redação do artigo, revisão crítica relevante do conteúdo intelectual e aprovação da versão final a ser publicada.

\section{Referências}

1. Trevizan MA, Almeida RG, Souza MC, Mazzo A, Mendes IA, Martins JC. Empathy in Brazilian nursing professionals: a descriptive study. Nurs Ethics. 2015;22(3):367-76.

2. Mufato LF, Gaíva MA. Empathy in health: integrative review. Rev Enferm Centro Oeste Mineiro. 2019;9:e2884.

3. Santo LD, Pohl S, Saiani L, Battistelli A. Empathy in the emotional interactions with patients. Is it positive for nurses too? J Nurs Educ Pract. 2014;4(2):74-81.

4. Zahavi D. Empathy and other-directed intentionality. Topoi. 2014;33:129-42.

5. Almeida FA, Moraes MS, Cunha ML. Taking care of the newborn dying and their families: nurses' experiences of neonatal intensive care. Rev Esc Enferm USP. 2016;50(Spe):122-29.

6. Dias IM, Fialho FA, Silva LR, Santos RS, Salvador M. Tecnologias aplicadas pela enfermagem no cuidado neonatal. Rev Baiana Enferm. 2015;29(1):23-32.

7. Jerusalinsky J. Detecção precoce de sofrimento psíquico versus patologização da primeira infância. Estilos Clínicos. 2018;23(1):83-99.

8. Sá Neto JA, Rodrigues BM. The intentional action of nursing team to caring for the newborn in the NICU. Cienc Cuid Saude. 2015;14(3):1237-44.

9. Green J, Darbyshire P, Adams A, Jackson D. Looking like a proper baby: nurses' experiences of caring for extremely premature infants. J Clin Nurs. 2015;24(1-2):81-9.

10. van Manen M. Researching lived experience: human science for an action sensitive pedagogy. 2nd ed. New York: Routledge; 2016.

11. Padoin SM, Terra MG, Paula CC, Langendorf TF, Siqueira DF, Motta $M G$, et al. Pesquisa qualitativa apoiada no referencial teórico da fenomenologia. In: Lacerda MR, Ribeiro RP, Costenaro RG. Metodologias da pesquisa para a enfermagem e saúde: da teoria à prática. Porto Alegre: Moriá; 2018. p. 233-62.

12. Malterud K, Siersma VD, Guassora AD. Sample size in qualitative interview studies: guided by information power. Qual Health Res. 2016;26(13):1753-60.

13. Cerbone DR. Fenomenologia. 3a ed. Rio de Janeiro: Vozes; 2014. (Série Pensamento Moderno).

14. Zahavi D. Self and other: from pure ego to co-constituied we. Cont Philos Rev. 2015;48(2):143-60.

15. van Manen MA. The First Cry of the Child. Qual Health Res. 2017;27(7):1069-76.

16. Schutz A. A construção significativa do mundo social: uma introdução à Sociologia compreensiva. Rio de Janeiro: Vozes; 2018.

17. Dames LJ, Alves VH, Rodrigues DP, Souza RR, Medeiros FV, Paiva ED. Nurses' practical knowledge on the clinical management of neonatal pain: a descriptive study. Online Braz $J$ Nurs. 2016;15(3):393-403. 